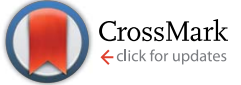

Cite this: J. Mater. Chem. A, 2017, 5, 11746

Received 9th January 2017

Accepted 17th February 2017

DOI: $10.1039 / \mathrm{cta00268h}$

rsc.li/materials-a

\section{Zinc-diffused silver indium selenide quantum dot sensitized solar cells with enhanced photoconversion efficiency $\dagger$}

\author{
Ganga Halder and Sayan Bhattacharyya*
}

Alloying of quantum dots (QDs) with suitable metal ions is one of the efficient tools to enhance the power conversion efficiency (PCE) of QD sensitized solar cells (QDSSCs). Ternary $\mathrm{Ag}_{\mathrm{ln}} \mathrm{X}_{2}(\mathrm{X}=\mathrm{S}, \mathrm{Se}$ ) based liquidjunction QDSSCs have low PCEs due to the presence of defect states at internal atom vacancies. However, $\mathrm{Zn}^{2+}$ diffusion at these vacant sites can improve the carrier mobility of the QDs. The QDSSCs with $\mathrm{Zn}^{2+}$ diffused $\mathrm{AgInSe}_{2}$ (ZAISE) QDs have a broad light harvesting range up to the near-infrared (NIR) range. PCE was enhanced from a merely $1.67 \%$ for pristine AglnSe $e_{2}$ QDs (AISE) to $3.07 \%$ for ZAISE with a $\mathrm{Zn} /(\mathrm{Ag}$ + In) ratio of $48.2 \%$, aided by an optimized $\mathrm{ZnS}$ passivation layer on the photoanode. The device efficiency was further improved to $3.57 \%$ by applying dual passivation of amorphous $\mathrm{TiO}_{2}$ and $\mathrm{SiO}_{2}$ layers. This approach could effectively suppress the recombination pathways at the QD surface and thereby minimize back electron transfer from photoexcited electrons of QDs and from the conduction band of $\mathrm{TiO}_{2}$ to the polysulfide electrolyte. The combined strategy of alloying with $\mathrm{Zn}^{2+}$ and inorganic passivation could achieve the highest ever PCE of environmentally friendly Agln $X_{2}$ based QDSSCs.

\section{Introduction}

Semiconductor QDs have size-controllable photophysical properties such as the tunability of their band gap, a high absorption coefficient, an ability to generate multiple excitons by a single photon and a large carrier lifetime which offers the possibility of boosting the PCE of photovoltaic devices beyond the Shockley-Queisser limit. ${ }^{1-5}$ In QDSSCs, narrow band gap cadmium and lead based chalcogenide semiconductors like $\mathrm{CdS}$, CdSe, $\mathrm{PbS}$, and PbSe are popularly employed as sensitizers and wider band gap metal oxide semiconductors like $\mathrm{TiO}_{2}, \mathrm{ZnO}$ and $\mathrm{SnO}_{2}$ are used as electron acceptors. ${ }^{6}$ However, the low to moderate PCE of these binary QDs lingers due to their limited light harvesting range and/or poor charge injection efficiency. In comparison, alloyed QDs are superior substitutes since their band gap can be tuned by changing their composition to obtain a broad light harvesting range and suitable band gap alignment for effective charge injection. ${ }^{7}$ Recently, copper and silver based ternary QDs have received attention for the fabrication of third generation photovoltaic devices due to their broad light harvesting range from the UV-visible to the NIR region. This broad

Department of Chemical Sciences and Centre for Advanced Functional Materials, Indian Institute of Science Education and Research (IISER) Kolkata, Mohanpur-741246, India.E-mail: sayanb@iiserkol.ac.in

$\dagger$ Electronic supplementary information (ESI) available: Powder XRD pattern of $\mathrm{Ag}_{2} \mathrm{Se}$; Tauc plots; PL spectra of AZ4 and AZ6 QDs synthesized at different temperatures; $J-V$ characteristics and variation of Nyquist plots, $R_{\mathrm{rec}}$ and $C_{\mu}$ as a function of the bias voltage of AZ5 QDSSCs with different ZnS SILAR cycles. See DOI: 10.1039/c7ta00268h range is very crucial for capturing a large number of solar photons. More importantly, these ternary alloyed QDs are free from toxic elements such as cadmium and lead which will open a new window for the commercial application of "non-toxic" QDs in QDSSCs for future environmental prospects. ${ }^{8-10}$

Although ternary alloyed QDs are good light harvesters, the efficiency of the photovoltaic devices is limited due to their high density of trap states which act as recombination centers in

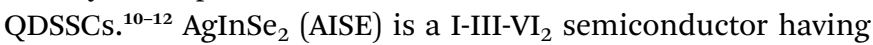
a direct bulk band gap of $1.19 \mathrm{eV}$, which is ideal for solar cell applications attributed to its high absorption coefficient. Although it has a broad light harvesting range, several vacancies at $\mathrm{Ag}$ and Se lattice sites along with internal atom vacancies lead to defect states. ${ }^{\mathbf{1 3 , 1 4}}$ In order to improve the PCE, silver chalcogenides were manipulated through creation of $\mathrm{Ag}_{2} \mathrm{~S}-\mathrm{AgInS}_{2}$ based $\mathrm{p}-\mathrm{n}$ junction heterostructures ${ }^{15,16}$ and $\mathrm{AgInS}_{2} \mathrm{QDs} / \mathrm{In}_{2} \mathrm{~S}_{3}$ based photoelectrodes, ${ }^{17}$ or introducing a buffer layer between AgInS $_{2}$ QD sensitizers and $\mathrm{ZnO}$ nanorod arrays. ${ }^{18}$ In spite of several efforts, the device efficiency is still low. The presence of defect states reduces the crystallinity, electrical conductivity and carrier mobility in ternary QDs. These trap states with a high density also act as recombination centers, thereby decreasing the photovoltage and photovoltaic performance. ${ }^{19,20}$ One of the ways to reduce the density of surface trap states is surface modification of ternary QDs where the passivation layers act as a barrier to minimize the electron and hole transfer rates. ${ }^{8,9,21}$

The diffusion of foreign metal ions into the vacant sites of ternary QD lattices is another suitable approach to improve the 
conductivity as well as PCE by minimizing the prevalent defect states. For example, Cu-diffused AISE QDs in organic/inorganic bulk-heterojunction devices decrease the internal resistance and increase the short-circuit current density $\left(J_{\mathrm{SC}}\right)$ under white light illumination. ${ }^{22}$ These alloying strategies alter the energy difference $\left(\Delta E_{\mathrm{CB}}\right)$ between the conduction energy levels of the QDs and metal oxide, henceforth increasing the injection efficiency of the photogenerated electrons. If $\Delta E_{\mathrm{CB}}$ is large enough, then photogenerated electrons can be rapidly injected into the metal oxide to enhance the charge collection efficiency and PCE. ${ }^{23}$ Although QDSSCs with ternary alloyed Zn-CuInSe ${ }_{2}$ QD sensitizers have already achieved $11.6 \%$ PCE through manipulation of the conduction band energy level, ${ }^{24}$ the breakthrough in AISE QD sensitized QDSSCs is much in demand to achieve improved PCE by increasing the crystallinity and carrier mobility of the QDs as well as by applying appropriate surface passivation.

In this work, $\mathrm{Zn}^{2+}$-diffused AgInSe ${ }_{2}$ (ZAISE) QDs with a broad light harvesting range from visible to NIR were synthesized by a hot injection method. The chemical composition of the QDs was varied by altering the ratio of $\mathrm{Zn} /(\mathrm{Ag}+\mathrm{In})$. Higher $\mathrm{Zn}$ diffusion increases the ZAISE band gap. Through different optimization steps, the best PCE obtained is $3.57 \%$ when the $\mathrm{Zn} /(\mathrm{Ag}+\mathrm{In})$ at $\%$ is 48.2. Our strategy could enhance the PCE of these "non-toxic" QDSSCs by $\sim 23 \%$ as compared to previous attempts.

\section{Results and discussion}

\subsection{Characterization of the QDs}

2.1.1 Structural characterization. A two-step in one pot synthetic procedure was employed for the preparation of ZAISE QDs. In the first step, the $\mathrm{Ag}_{2} \mathrm{Se}$ QDs were synthesized within 3 min at $88{ }^{\circ} \mathrm{C}$ from the reaction between Ag-oleylamine complex solution with very reactive phosphine-free Se-precursor. The Seprecursor was obtained from the reduction of Se powder by a $1: 1$ mixture of oleylamine and dodecanethiol. The $\mathrm{Ag}_{2} \mathrm{Se}$ QDs crystallize in the orthorhombic crystal structure according to JCPDS pattern 24-1041 (Fig. S1 $\dagger$ ). Thereafter the reaction mixture was further heated to $180^{\circ} \mathrm{C}$ for the diffusion of $\mathrm{In}^{3+}$ and $\mathrm{Zn}^{2+}$ into the $\mathrm{Ag}_{2} \mathrm{Se}$ crystal lattice to form ZAISE QDs. Since the ionic radii of $\mathrm{In}^{3+}$ and $\mathrm{Zn}^{2+}$ are 1.44 and $0.68 \AA$, respectively, these ions can easily diffuse into the vacant sites of $\mathrm{Ag}_{2}$ Se where the ionic radius of $\mathrm{Ag}^{+}$is $1.54 \AA^{25,26}$ The QD samples denoted as AZ0, AZ4, AZ5 and AZ6 have a $\mathrm{Zn}:(\mathrm{Ag}+\mathrm{In})$ at\% of $0,36,48$ and 58, respectively, as obtained by inductively coupled plasma mass spectrometry (ICP-MS) analyses. The powder X-ray diffraction (XRD) patterns in Fig. 1a show that all the QDs crystallize in the tetragonal crystal structure (Fig. 1b) with space group $I \overline{4} 2 d$ according to the JCPDS pattern 75-0118. ICP-MS data show that on moving from AZ0 to AZ5, the drop in Ag: $(\mathrm{Ag}+\mathrm{In}+\mathrm{Zn})$ is $30 \%$ whereas that of $\mathrm{In}:(\mathrm{Ag}+$ $\mathrm{In}+\mathrm{Zn}$ ) is $70 \%$. Therefore it is evident that a majority of $\mathrm{Zn}^{2+}$ sits in the $\mathrm{In}^{3+}$ sites than at $\mathrm{Ag}^{+}$sites, and the relatively closer ionic radii of $\mathrm{In}^{3+}$ and $\mathrm{Zn}^{2+}$ are another validation to this argument. Also, the simultaneous diffusion of $\mathrm{In}^{3+}$ and $\mathrm{Zn}^{2+}$ in the $\mathrm{Ag}_{2} \mathrm{Se}$ lattice provides a competition between them to occupy the lattice vacancies. The crystallite size of the QDs is 3.2-3.5 $\mathrm{nm}$ which is calculated from the powder XRD pattern of the QDs using the Debye-Scherrer equation after subtracting the instrumental broadening. The representative transmission electron micrographs (TEMs) show that the particle size of the monodisperse QDs is around 4-6 $\mathrm{nm}$ with a moderately narrow size distribution (Fig. 1c and e). The AISE and ZAISE QDs were ligand-exchanged by replacing the initial hydrophobic oleylamine surfactant with mercaptopropionic acid (MPA) in order to obtain a maximum loading of the QDs on the $\mathrm{TiO}_{2}$ substrate and improve the film conductivity of QDSSCs. ${ }^{27}$ The interplanar spacing shows the high crystallinity and the indexed fast Fourier transform (FFT) patterns (Fig. 1d and f) confirm the purity of the as-synthesized QDs.

2.1.2 Optical characterization. The absorption spectra of all the QDs synthesized at $180{ }^{\circ} \mathrm{C}$ (Fig. 2a and $\mathrm{S} 2 \dagger$ ) show a broad light harvesting range from visible to NIR, an essential requirement to achieve high efficiency QDSSCs. The band gap of AZ0, AZ4, AZ5 and AZ6 is 1.50, 1.50, 1.53, and $1.56 \mathrm{eV}$ as measured from the Tauc plots (Fig. S3a $\dagger$ ). To evaluate the
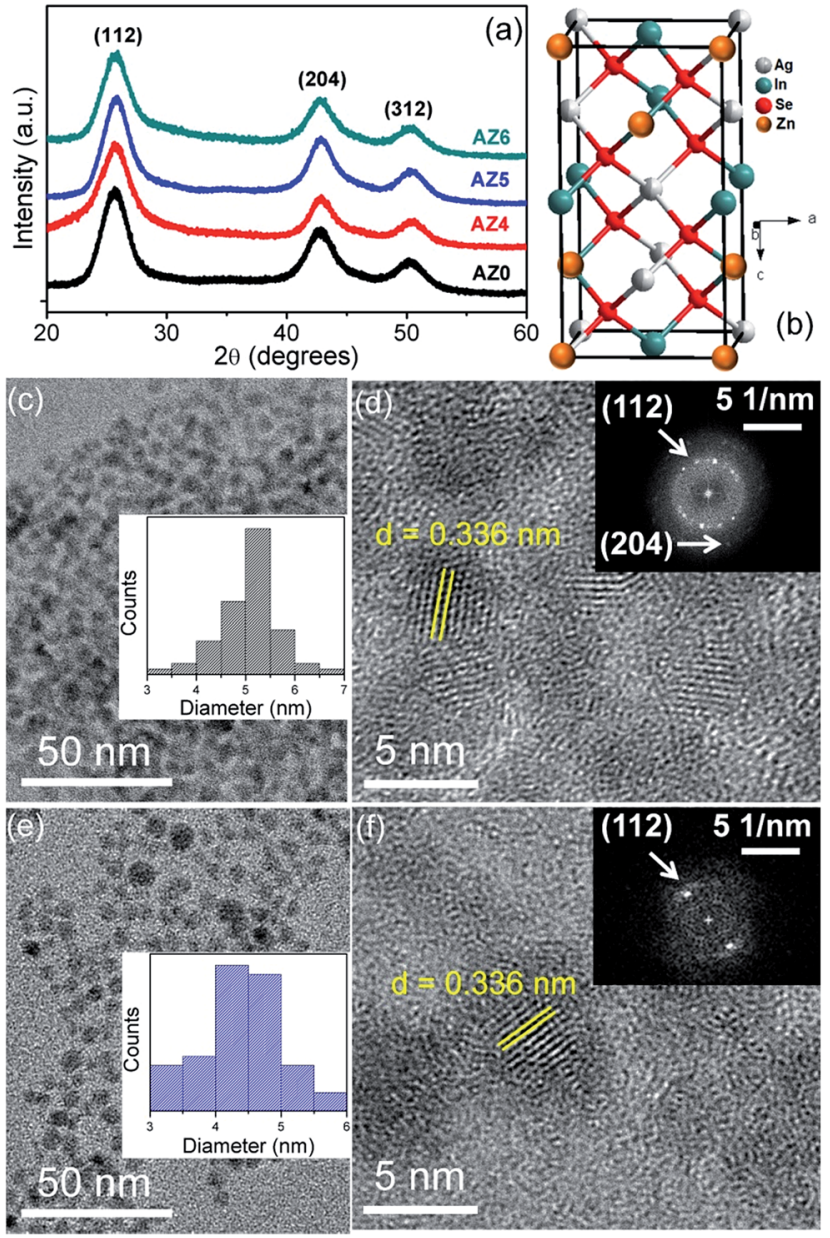

Fig. 1 (a) Powder XRD patterns of the QDs. (b) Representative unit cell of AZ5. (c) Low resolution TEM image of AZO with the diameter histogram as the inset. (d) High resolution TEM image of AZO with the FFT pattern as the inset. (e) Low resolution TEM image of AZ5 with the diameter histogram as the inset. (f) High resolution TEM image of AZ5 with the FFT pattern as the inset. 

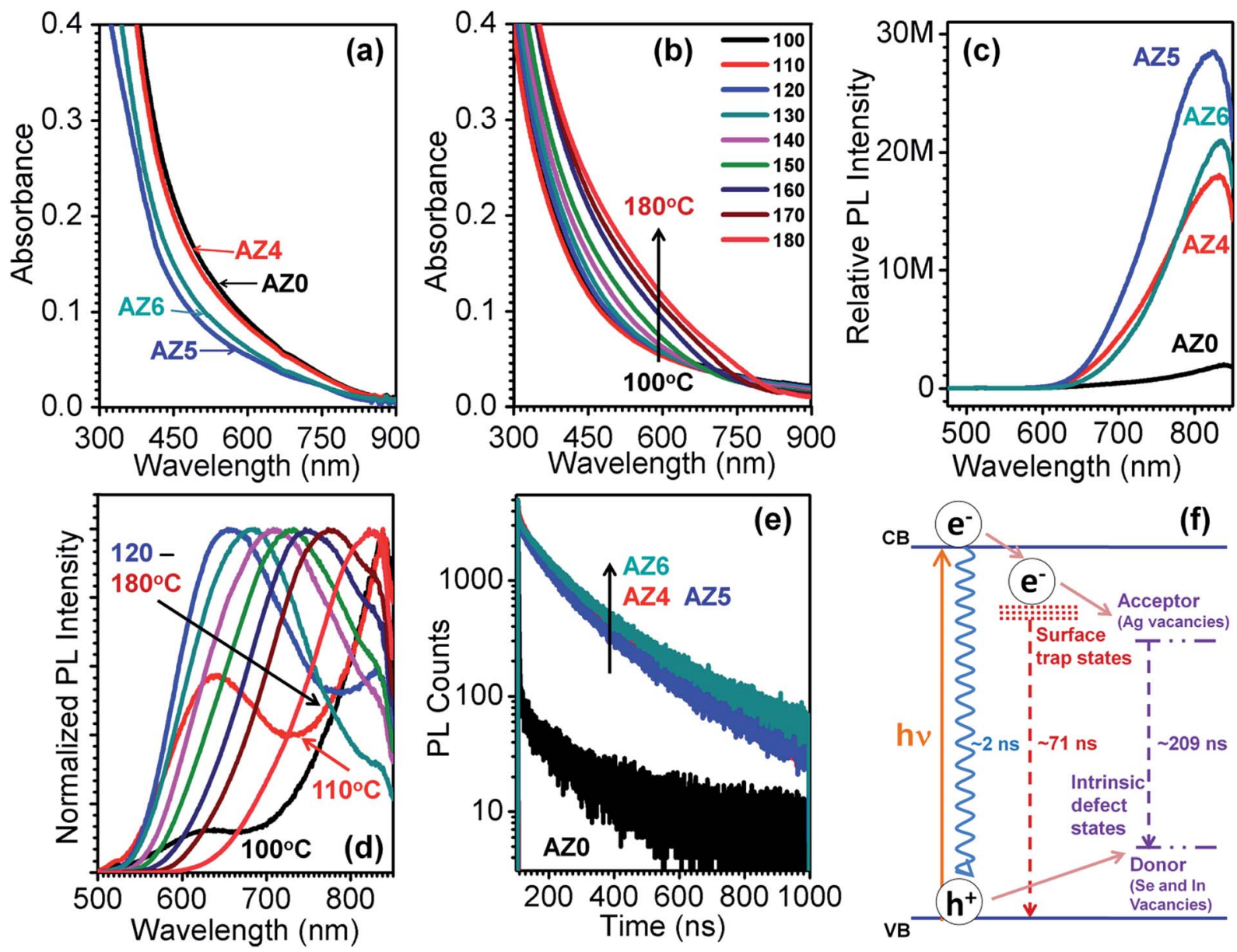

Fig. 2 (a) Absorption spectra of the colloidal QDs synthesized at $180^{\circ} \mathrm{C}$. (b) Reaction temperature dependent absorption spectra of AZ5 QDs. (c) Relative PL intensity plot of the QDs. (d) Reaction temperature dependent PL spectra of AZ5 QDs. Excitation wavelength: $\lambda_{\text {ex }}=450 \mathrm{~nm}$. (e) PL lifetime decay plots of colloidal QDs. All spectra were recorded in chloroform. (f) Schematic energy level diagram (not to scale) showing the recombination pathways.

impact of synthesis temperature and resultant particle size on the band gap, the absorption spectra of AZ5 QDs were recorded with the aliquots at different reaction temperatures. Fig. $2 \mathrm{~b}$ shows the reaction temperature dependent UV-Vis-NIR spectra of AZ5 QDs. Due to the increase of the particle size at higher temperatures, the light harvesting range becomes broader. As a result the band gap decreases from $2 \mathrm{eV}$ at $100^{\circ} \mathrm{C}$ to $1.53 \mathrm{eV}$ at $180{ }^{\circ} \mathrm{C}$ (Fig. S3b $\dagger$ ). Among the AZ0-AZ6 QDs synthesized at $180{ }^{\circ} \mathrm{C}$, AZ5 shows the maximum photoluminescence (PL) intensity (Fig. 2c). With higher incorporation of $\mathrm{Zn}^{2+}$ ions, the peak position is slightly blue shifted from AZ0 to AZ6 QDs. ${ }^{28}$ The room temperature emission spectra of AZ5 QDs were also recorded by taking the aliquots at different reaction temperatures (Fig. 2d). Two distinct emission bands are observed with QDs from aliquots at 100 and $110{ }^{\circ} \mathrm{C}$. The band at higher wavelengths can be attributed to the emission from cation vacancy defects, since at $100-110{ }^{\circ} \mathrm{C}, \mathrm{Zn}^{2+}$ ions have minimum probability to enter the vacant sites. The emission band at lower wavelengths arises from donor-acceptor pair recombination within the band gap with $\mathrm{Ag}^{+}$vacancies as the acceptor, and $\mathrm{Se}^{2-}$ and $\mathrm{In}^{3+}$ vacancies as donors (Fig. 2d). ${ }^{29}$ The intensity of the lower wavelength band gradually increases with an increase in the reaction temperature which indicates higher incorporation of $\mathrm{Zn}^{2+}$ and $\mathrm{In}^{3+}$ into the vacant sites of $\mathrm{Ag}_{2} \mathrm{Se}^{14,28,30} \mathrm{At}$ elevated temperatures, these two bands merge into a broad intense emission band. This broad emission band (full width at half maxima $>100 \mathrm{~nm}$ ) is an indication of the formation of alloyed QDs. ${ }^{30}$ The peak maximum is gradually red shifted due to the faster growth of QDs at higher temperatures. The reaction temperature dependent PL spectra of AZ4 and AZ6 QDs (Fig. S4 $\dagger$ ) show a similar trend to that of AZ5.

Fig. 2e shows the fluorescence decay curves of all the QDs at an excitation wavelength of $402 \mathrm{~nm}$. The PL decay was recorded at $840,834,832$ and $830 \mathrm{~nm}$ for AZ0, AZ4, AZ5 and AZ6 QDs, respectively. The PL decay profiles are found to be triexponential with an average lifetime of 232.7, 180.1, 184.8 and $203.9 \mathrm{~ns}$ for AZ0, AZ4, AZ5 and AZ6 QDs, respectively (Table 1). Fig. $2 \mathrm{f}$ provides the schematic energy level diagram showing the three recombination pathways with different lifetimes $(\tau)$ and their amplitude $(A)$. The faster decay component $\left(\tau_{3} \sim 2 \mathrm{~ns}\right)$ arises due to non-radiative processes e.g. Auger recombination and its contribution $\left(A_{3}\right)$ is the highest in AZ0. In AZ4 to AZ6, the contribution of this component is dominated by surface trap state emission $\left(\tau_{1} \sim 66.6-75.6 \mathrm{~ns}\right)$ and donor-acceptor 
Table 1 PL lifetime decay parameters of QDs synthesized at $180^{\circ} \mathrm{C}$

\begin{tabular}{lllllllll}
\hline QD code & $A_{1}$ & \multirow{2}{*}{$\tau_{1}(\mathrm{~ns})$} & \multicolumn{1}{l}{$A_{2}$} & $\tau_{2}(\mathrm{~ns})$ & \multicolumn{1}{c}{$A_{3}$} & $\tau_{3}(\mathrm{~ns})$ & $\chi^{2}$ & $\langle\tau\rangle(\mathrm{ns})$ \\
\hline AZ0 & 12.68 & 37.7 & 53.15 & 240.8 & 34.17 & 1.33 & 1.13 & 232.7 \\
AZ4 & 29.49 & 66.6 & 69.65 & 196.4 & 0.85 & 2.67 & 1.04 & 180.1 \\
AZ5 & 30.68 & 67.9 & 68.23 & 202.5 & 1.09 & 1.69 & 1.09 & 184.8 \\
AZ6 & 29.08 & 75.6 & 70.07 & 222.1 & 0.85 & 1.94 & 1.06 & 203.9
\end{tabular}

recombination $\left(\tau_{3} \sim 196.4-222.1 \mathrm{~ns}\right)$ between the $\mathrm{Ag}^{+}$vacancies as donor sites and $\mathrm{In}^{3+}$ and $\mathrm{Se}^{2-}$ vacancies as acceptor sites. ${ }^{31} \mathrm{In}$ the absence of $\mathrm{Zn}^{2+}(\mathrm{AZ0})$ the contributions from surface trap state emission and donor-acceptor recombination to the total average lifetime are lower as compared to those of AZ4-AZ6. Since $\tau_{2}$ increases from $196.4 \mathrm{~ns}$ to $222.1 \mathrm{~ns}$ for AZ4 to AZ6 QDs, respectively, it is evident that $\mathrm{Zn}^{2+}$ diffusion in the $\mathrm{In}^{3+}$ and $\mathrm{Ag}^{+}$ sites allows lesser donor-acceptor recombination. However, the contribution of surface trap state emission $\left(A_{1}\right)$ increases from 12.7 for AZ0 to 29.1-30.7 for AZ4-AZ6. The variation of $\tau_{1}$ and $A_{1}$ implies that $\mathrm{Zn}^{2+}$ ions occupy surface sites till saturation before diffusing to the vacancy sites inside the $\mathrm{AgInSe} \mathrm{S}_{2}$ lattice. This is manifested from similar band gaps of AZ0 and AZ4, before increasing for $\mathrm{AZ} 5$ and $\mathrm{AZ6} 6 \mathrm{by} \mathrm{Zn}^{2+}$ lattice diffusion. In this case, segregation of a separate ZnSe phase at the QD surface is possible; however no such evidence is obtained from the XRD patterns in Fig. 1a.

\subsection{Photovoltaic performance of the QDs}

The working electrodes were prepared by dip coating of the asprepared $\sim 9 \mu \mathrm{m}$ thick $\mathrm{TiO}_{2}$ films on fluorine-doped tin oxide (FTO) coated glass substrates in aqueous dispersions of MPA- capped QDs. With the counter electrode made of a paste of microwave synthesized CuS powder ${ }^{32}$ and the sandwiched droplet of the electrolyte between the working and counter electrodes, at first the performance of AZ0-AZ6 based QDSSCs was tested. Here 8 cycles of $\mathrm{ZnS}$ passivation layers were applied on the working electrode by successive ionic layer adsorption and reaction (SILAR). Second, the number of ZnS SILAR cycles was optimized with the best performing QDs. In the third step, a double inorganic passivation of amorphous $\mathrm{TiO}_{2}$ and $\mathrm{SiO}_{2}$ was applied to further enhance the photovoltaic performance. Electrochemical impedance spectroscopy (EIS) was used to explain the trends and the role of passivation.

2.2.1 Performance of AISE and ZAISE QDSSCs. The current density $(J)$-voltage $(V)$ characteristics of the QDSSCs fabricated with AZ0-AZ6 QDs are shown in Fig. 3a. The open circuit voltage $\left(V_{\mathrm{OC}}\right), J_{\mathrm{SC}}$, fill factor $(\mathrm{FF})$ and PCE $(\eta \%)$ of the QDSSCs are tabulated in Table 2 where $8 \mathrm{ZnS}$ SILAR cycles were applied in all the QDSSCs. The variation of all the solar cell parameters is shown in Fig. $3 \mathrm{~b}$ and $\mathrm{c}$ as a function of $\mathrm{Zn} /(\mathrm{Ag}+\mathrm{In})$ at\%. $V_{\mathrm{OC}}$ increases from $0.30 \mathrm{~V}$ for AZ0 to $0.37 \mathrm{~V}$ for AZ5 films and decreases for AZ6. The photocurrent also shows a similar trend where the highest $J_{\mathrm{SC}}$ is observed for AZ5 $\left(15.78 \mathrm{~mA} \mathrm{~cm}^{-2}\right)$ as compared to AZ0 (9.91 $\mathrm{mA} \mathrm{cm} \mathrm{cm}^{-2}$ ). The photovoltaic performance was observed to be the highest for AZ5 QDSSCs (3.07\%) which is $45.6 \%$ more than that of AZ0 QDSSCs (1.67\%).

The EIS measurements were carried out in the dark to highlight the significant improvement of the device efficiency upon zinc incorporation into the QDs. ${ }^{33}$ Fig. 3d shows the Nyquist plots recorded in the frequency range from $0.1 \mathrm{~Hz}$ to 1 $\mathrm{MHz}$ at a forward bias of $-0.35 \mathrm{~V}$, which is very close to the $V_{\mathrm{OC}}$ of the QDSSCs. The Nyquist plots are fitted with an equivalent
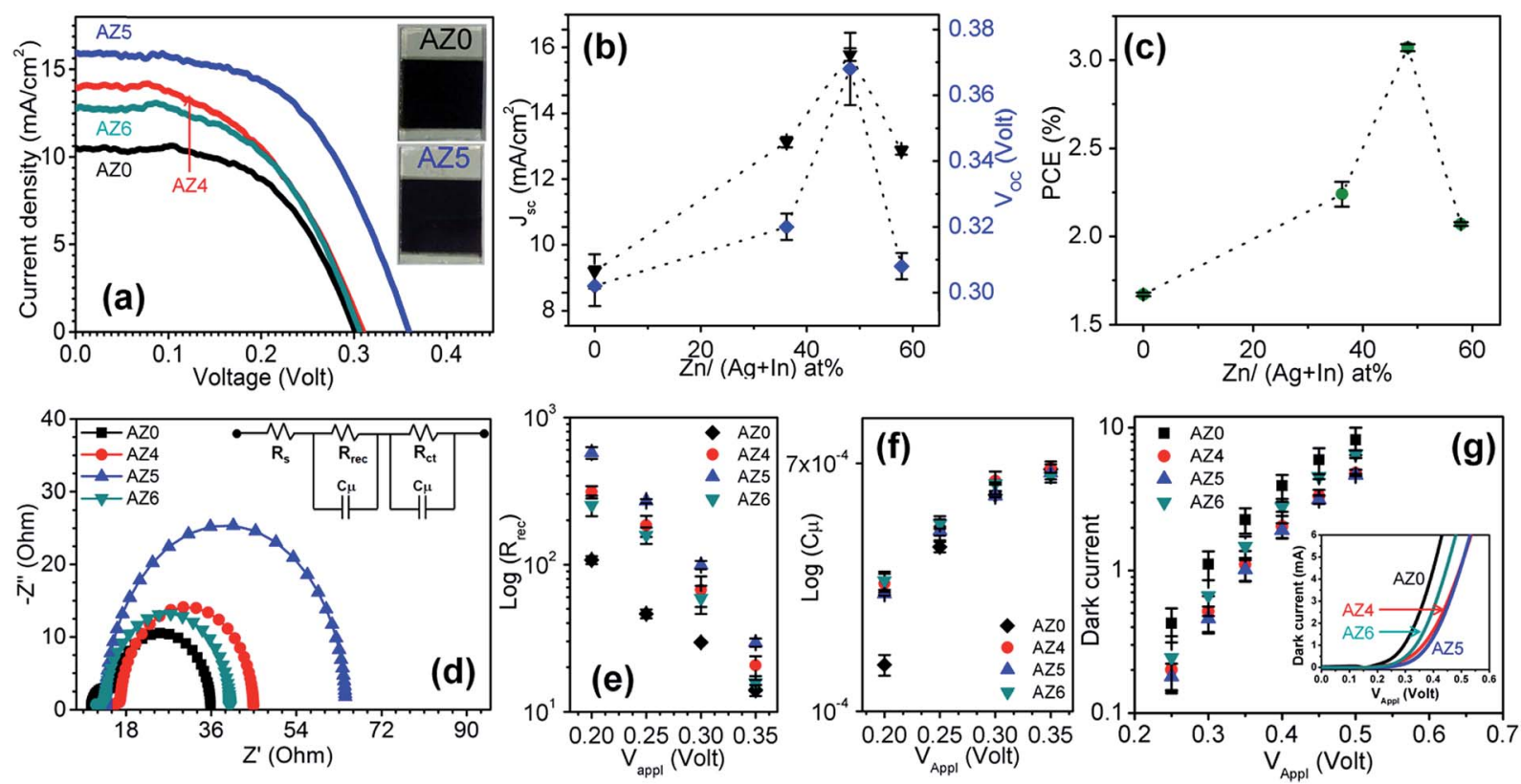

Fig. 3 (a) J-V characteristics of the QDSSCs under 1 sun illumination. (Inset) Digital images of AZO and AZ5 photoanodes. Variation of the (b) J $J_{S C}$ and $V_{\mathrm{OC}}$, and (c) PCE of the QDSSCs as a function of $\mathrm{Zn} /(\mathrm{Ag}+\mathrm{In}) \mathrm{at} \%$. (d) Nyquist plot of the QDSSCs at $-0.35 \mathrm{~V}$ forward bias under dark conditions with the equivalent circuit as the inset. Plots of the (e) recombination resistance and (f) chemical capacitance of the QDSSCs with applied potential. (g) Variation of dark current with applied potential in the log scale (inset shows the normal scale). 
Table 2 QDSSC parameters after treatment of 8 ZnS cycles by SILAR

\begin{tabular}{lcrrr}
\hline QDSSCs & Zn/(Ag + In) at $\%$ & $J_{\text {SC }}\left(\mathrm{mA} \mathrm{cm}^{-2}\right)$ & $V_{\text {OC }}(\mathrm{V})$ & FF \\
\hline AZ0 & 0 & $9.91 \pm 0.54$ & $0.302 \pm 0.004$ & $0.555 \pm 0.006$ \\
AZ4 & 36.2 & $13.13 \pm 0.16$ & $0.320 \pm 0.004$ & $0.526 \pm 0.013$ \\
AZ5 & 48.2 & $15.78 \pm 0.19$ & $0.368 \pm 0.011$ & $0.529 \pm 0.013$ \\
AZ6 & 57.9 & $12.87 \pm 0.13$ & $0.308 \pm 0.004$ & $0.520 \pm 0.007$
\end{tabular}

${ }^{a}$ Average of three cells in parallel.

circuit as shown in the Fig. 3d inset. All the EIS parameters e.g. series resistance $\left(R_{\mathrm{s}}\right)$, charge recombination resistance at photoanode and electrolyte interfaces $\left(R_{\text {rec }}\right)$, and chemical capacitance $\left(C_{\mu}\right)$ are tabulated in Table 3. No significant change of $R_{\mathrm{s}}$ is observed for different QDSSCs since it depends upon the transport resistance of FTO and the connection setup which is equivalent for all the measurements. However, a considerably higher $R_{\text {rec }}$ is observed in ZAISE than AISE QDSSCs (Fig. 3e). Since $R_{\text {rec }}$ is inversely proportional to the charge recombination rate, the latter becomes sluggish at the interface of the ZAISE photoanode and the electrolyte than with the AISE photoanode. The photovoltaic data shown in Table 2 can be directly correlated with $R_{\text {rec }}$ data which shows the significant improvement of the efficiency of ZAISE based devices. The $C_{\mu}$ of all the QDSSCs is similar at different applied voltages (Fig. 3f), due to the unchanged $\mathrm{TiO}_{2}$ conduction band position with different QD sensitizers. As a cross-check on the recombination rate in QDSSCs, their $I-V$ characteristics were also measured in the dark (Fig. 3g inset) and the dark or recombination current is plotted as a function of applied voltage (Fig. 3g). The dark current in ZAISE QDSSCs is less than that in AISE QDSSCs at the same applied voltage which further proves the slower charge recombination at the photoanode/electrolyte interfaces in ZAISE QDSSCs.

The relatively higher efficiency of AZ5 QDSSCs even though the average lifetime of AZ5 colloidal QDs is lower than those of AZ0 and AZ6 is quite intriguing (Table 1). When the QD surface layer is passivated by $8 \mathrm{ZnS}$ SILAR cycles, the surface trap state recombination is reduced. Since AZ5 has a relatively higher contribution of $\tau_{1}$, the QDSSCs with AZ5 QDs are mostly benefitted. Interestingly in this work, a total of $8 \mathrm{ZnS}$ SILAR cycles are required to make a well passivated layer on the QD surface whereas there are reports where $4 \mathrm{ZnS}$ SILAR cycles are employed to achieve the highest device efficiency. ${ }^{2,34,35}$ This clearly highlights the importance of reducing the surface trap state emission. The surface passivation however cannot alter the $\tau_{2}$ and $\tau_{3}$ components i.e. non-radiative and donor-acceptor recombination processes which are inherent to the QDs with a specific $\mathrm{Zn}^{2+}$ concentration. Due to the reduction in surface trap states, slower charge recombination occurs at the $\mathrm{TiO}_{2} / \mathrm{QD} /$ electrolyte interface which increases the PCE of AZ5-8Z QDSSCs. On the other hand, due to a large amount of non-radiative loss, PCE is the least for AZ0-8Z QDSSCs (Table 2).

2.2.2 Variation of ZnS SILAR cycles. To probe the extent of passivation, the number of the ZnS SILAR cycles was varied and applied onto the AZ5-fabricated QDSSCs. The cells are denoted as AZ5-4Z, AZ5-8Z and AZ5-10Z for 4, 8 and 10 ZnS SILAR cycles, respectively. The photocurrent increases by $31.2 \%$ from AZ5- $4 Z$ to AZ5-8Z (Table S1†) due to surface passivation of unsaturated dangling bonds and surface trap states of the QDs. $V_{\mathrm{OC}}$ also increases from $0.34 \mathrm{~V}$ for AZ5-4Z to $0.37 \mathrm{~V}$ for AZ5-8Z whereas FF also shows a similar trend. From AZ5-8Z to AZ5-10Z, although $J_{\mathrm{SC}}$ and $\mathrm{FF}$ remain almost constant, $V_{\mathrm{OC}}$ decreases. Thus, the overall PCE is the highest with $8 \mathrm{ZnS}$ cycles (Fig. S5†). $R_{\text {rec }}$ is significantly higher for AZ5-8Z and AZ5-10Z compared to AZ54Z. However $C_{\mu}$ is lower for AZ5-10Z at different applied voltages, a trend similar to an earlier report for $\mathrm{CuInSe}_{2}$ QDSSCs with a higher number of $\mathrm{ZnS}$ cycles. ${ }^{36}$ The deposition of passivation layers beyond the optimum thickness can partially block the $\mathrm{TiO}_{2}$ pores leading to poor infiltration of the electrolyte. $^{2} 10 \mathrm{ZnS}$ SILAR cycles can agglomerate the QDs which limits the interfacial contact between porous $\mathrm{TiO}_{2}$ and the polysulfide electrolyte and therefore with a limiting charge injection propensity, PCE does not improve beyond that of AZ5-8Z. The blocking of pores may promote processes such as auger recombination or radiative recombination due to the presence of long lived holes in the ZAISE QDs and limited hole transfer from QDs to the electrolyte. ${ }^{35}$

2.2.3 Effect of $\mathrm{TiO}_{2} / \mathrm{SiO}_{2}$ double passivation. With the goal to improve the PCE beyond $3.07 \%$, the photoanode containing 8

Table 3 EIS parameters of QDSSCs after different post treatment processes

\begin{tabular}{llllr}
\hline QDSSCSs & $R_{\mathrm{s}}\left(\Omega \mathrm{cm}^{-2}\right)$ & $R_{\text {rec }}\left(\Omega \mathrm{cm}^{-2}\right)$ & $C_{\mu}\left(\mathrm{mF} \mathrm{cm}^{-2}\right)$ & $f_{\text {max }}(\mathrm{Hz})$ \\
\hline AZ0-8Z & 10.65 & 12.58 & 0.70 & 12.12 \\
AZ4-8Z & 15.34 & 17.06 & 0.64 & 8.25 \\
AZ5-8Z & 12.25 & 30.78 & 0.68 & 5.62 \\
AZ6-8Z & 11.88 & 15.98 & 0.62 & 13.11 \\
AZ5-4Z & 12.1 & 21.58 & 0.67 & 19.26 \\
AZ5-10Z & 14.8 & 27.61 & 0.63 & 28.27 \\
AZ5-8ZTS & 12.75 & 46.87 & 0.65 & 6.81 \\
\end{tabular}


ZnS SILAR cycles was enriched with amorphous $\mathrm{TiO}_{2}$ and $\mathrm{SiO}_{2}$ passivation layers to make AZ5-8ZTS cells. These double passivation layers increase both $J_{\mathrm{SC}}$ and $V_{\mathrm{OC}}$ as shown in Fig. $4 \mathrm{a}$ and tabulated in Table 4. A very significant change in FF is observed from 0.53 for AZ5-8Z to 0.59 for AZ5-8ZTS. By following these techniques, the best PCE of $3.57 \%$ is achieved for AZ58ZTS QDSSCs which is $15.9 \%$ higher than that of AZ5-8Z QDSSC. Likewise the charge recombination is also reduced as shown in Fig. $4 \mathrm{~b}$ and c. Although $R_{\text {rec }}$ does not improve from 8 to $10 \mathrm{ZnS}$ cycles, a very thin $\mathrm{SiO}_{2}$ layer on top of 8 cycles of $\mathrm{ZnS}$ can slow down the recombination rate by saturating the dangling bonds through $\mathrm{Ti}-\mathrm{S}$ and $\mathrm{Zn}-\mathrm{O}$ bond formation without any change in $C_{\mu}$ (Fig. $4 \mathrm{~d}$ ). The lifetime of the electrons $\left(\tau_{\mathrm{n}}\right)$ is calculated from the Bode plot (Fig. 4e) by using eqn (1):

$$
\tau_{\mathrm{n}}=1 /\left(2 \pi f_{\max }\right)
$$

where $f_{\max }$ is the frequency maxima of the lower frequency peak in the Bode plot. The calculated lifetime of AZ0-8Z, AZ5-8Z and AZ5-8ZST QDSSCs is 13.1, 28.3 and $41.5 \mathrm{~ms}$, respectively (Table $3)$. This higher recombination lifetime of the electrons further confirms the slower charge recombination processes after applying amorphous $\mathrm{TiO}_{2}$ on top of the QD layer and $\mathrm{SiO}_{2}$ on the $\mathrm{ZnS}$ layer. This result is further supported by the dark current measurements at different applied voltages (Fig. 4f).

Several charge recombination processes which are responsible for the low PCE of QDSSCs include band edge recombination between the valence band holes and the conduction band electrons in QDs, back electron transfer to the electrolyte
Table 4 QDSSC parameters for AZO and AZ5 after different post treatments

\begin{tabular}{lllll}
\hline QDSSCs & $J_{\text {SC }}\left(\mathrm{mA} \mathrm{cm}^{-2}\right)$ & $V_{\mathrm{OC}}(\mathrm{V})$ & $\mathrm{FF}$ & $\eta(\%)$ \\
\hline AZ0-8Z & $9.91 \pm 0.54$ & $0.302 \pm 0.004$ & $0.555 \pm 0.006$ & $1.67 \pm 0.10$ \\
AZ5-8Z & $15.78 \pm 0.19$ & $0.368 \pm 0.011$ & $0.529 \pm 0.013$ & $3.07 \pm 0.02$ \\
AZ5-8ZTS $^{a}$ & $15.78 \pm 0.23$ & $0.378 \pm 0.002$ & $0.576 \pm 0.016$ & $3.41 \pm 0.16$ \\
AZ5-8ZTS $^{b}$ & 16.03 & 0.381 & 0.585 & 3.57
\end{tabular}

${ }^{a}$ Average of three cells in parallel. ${ }^{b}$ Champion cell.

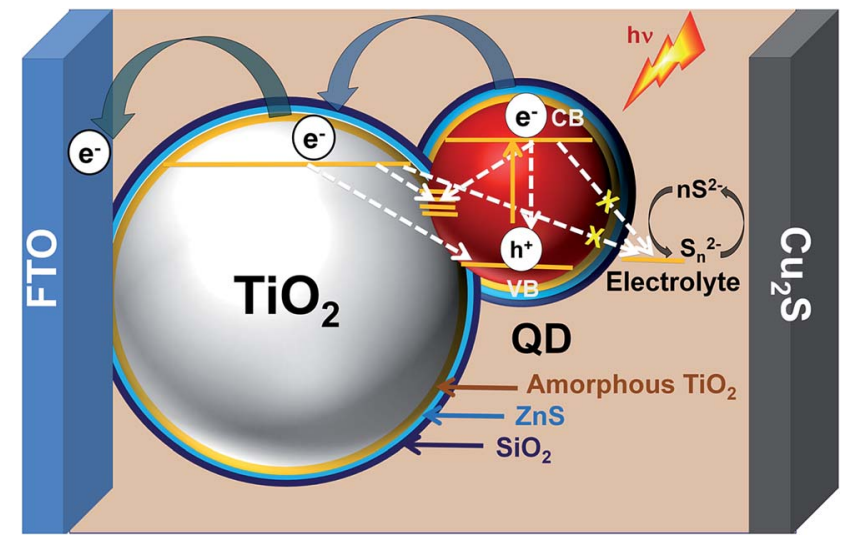

Fig. 5 Schematic of the AZ5-8ZTS based QDSSC showing the electron transfer (solid curved arrows) and recombination pathways (dotted straight arrows).
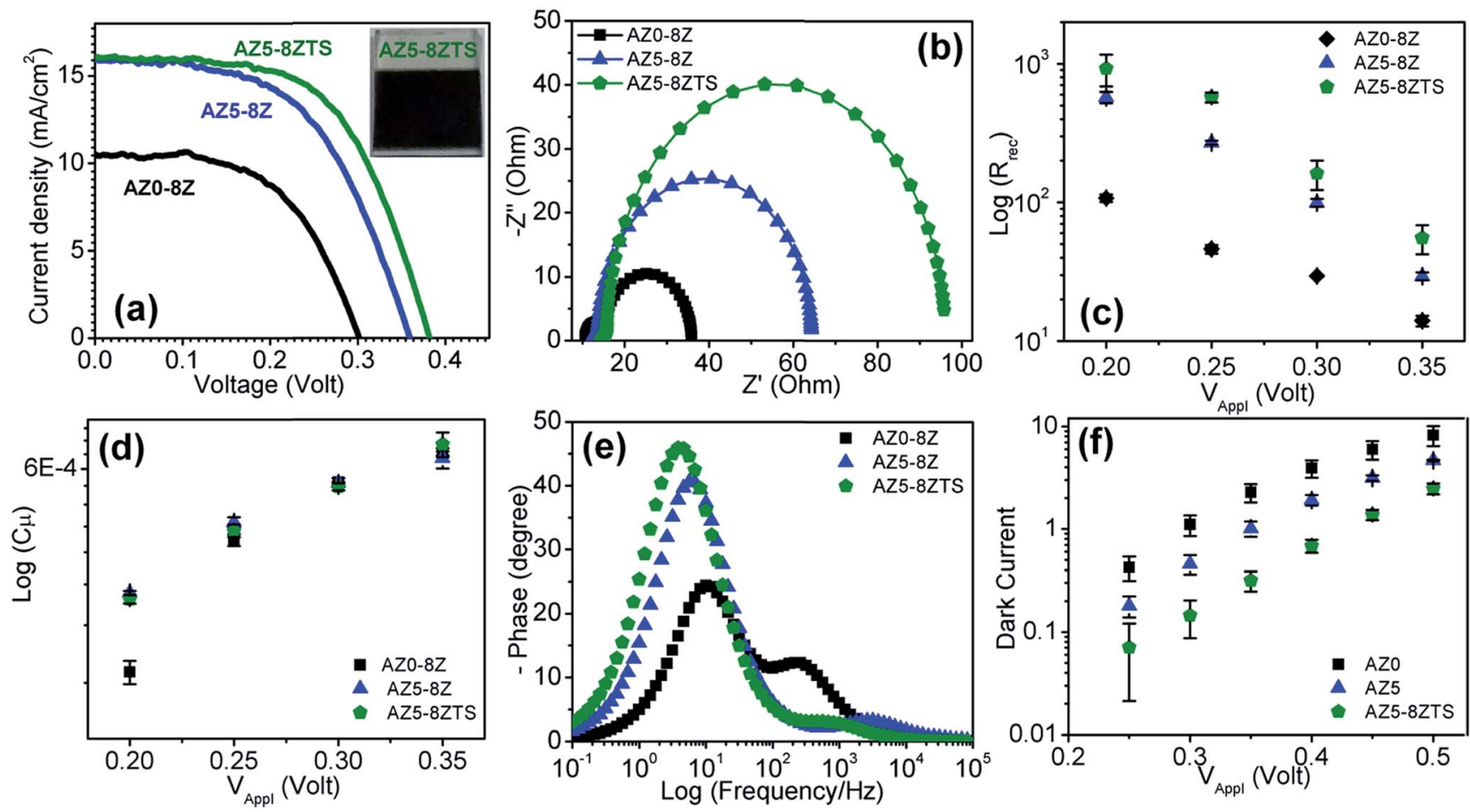

Fig. 4 (a) J-V characteristics of the representative QDSSCs under 1 sun illumination. (Inset) Digital image of the AZ5-8ZTS photoanode. (b) Nyquist plot of the QDSSCs at $-0.35 \mathrm{~V}$ forward bias under dark conditions. Plots of the (c) recombination resistance and (d) chemical capacitance of the QDSSCs with applied potential. (e) Bode plots of the QDSSCs. (f) Variation of dark current with applied potential in the log scale. 
Table 5 Review of literature reports on $\mathrm{AglnS}_{2} / \mathrm{Se}_{2}$ solar cells

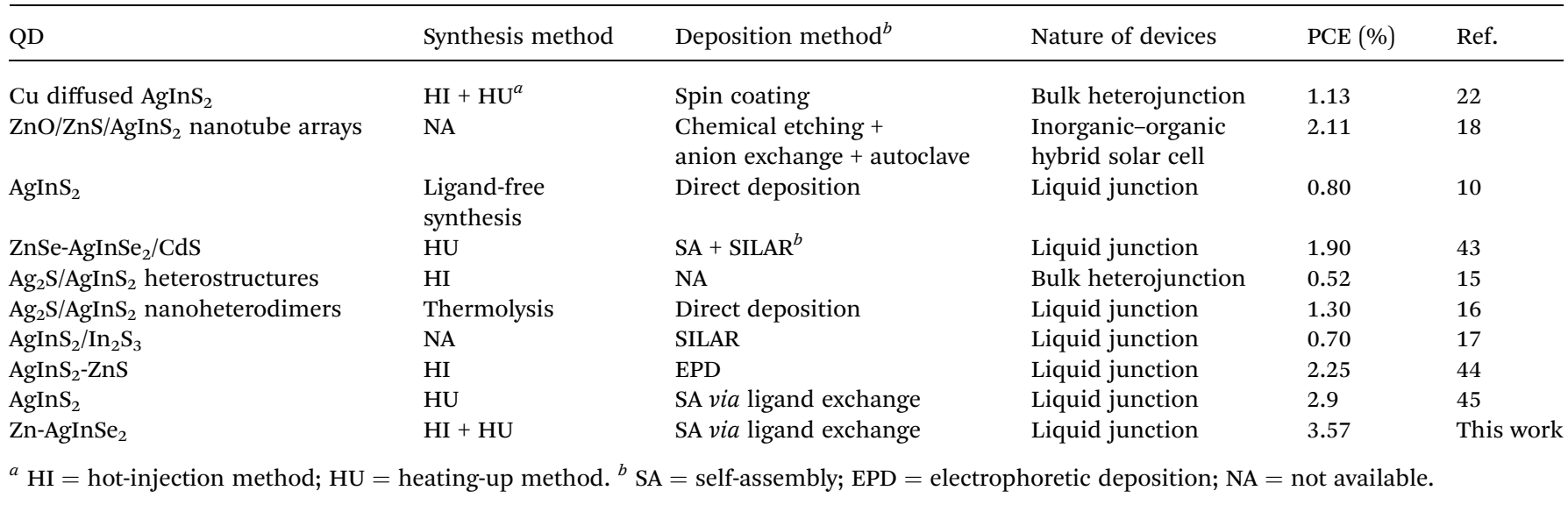

from photoexcited electrons of QDs and from the conduction band of $\mathrm{TiO}_{2}$, recombination of conduction band electrons of $\mathrm{TiO}_{2}$ with the valence band hole of QDs, and surface trapping of photoexcited electrons of QDs and conduction band electrons of $\mathrm{TiO}_{2} \cdot{ }^{37}$ The modification of the photoanode surface with suitable inorganic and organic passivation layers is a key step to suppress these charge recombination pathways and improve the device efficiency. ${ }^{38-40}$ Inorganic passivation can suppress a majority of these recombination pathways which indeed is the key step to enhance the PCE of QDSSCs. ${ }^{34,41,42}$ In this work, when $\mathrm{ZnS}$ is deposited by SILAR onto the QD-coated $\mathrm{TiO}_{2}$ substrate, it likely passivates the dangling bonds present on the $\mathrm{TiO}_{2}$ surface through the formation of well-ordered $\mathrm{Zn}-\mathrm{O}$ and $\mathrm{S}-\mathrm{Ti}$ bonds. The amorphous $\mathrm{TiO}_{2}$ coating, on the QD-deposited $\mathrm{TiO}_{2}$ photoanode, acts as a buffer layer at the interface between $\mathrm{TiO}_{2} / \mathrm{QDs}$ and $\mathrm{ZnS} / \mathrm{SiO}_{2}$ thus reducing the interfacial trap states to enhance the device efficiency. Further, the deposition of $\mathrm{SiO}_{2}$ on $\mathrm{ZnS}$ can passivate all the exposed $\mathrm{Zn}$ and $\mathrm{S}$ surface atoms through the formation of $\mathrm{Si}-\mathrm{S}$ and $\mathrm{O}-\mathrm{Zn}$ bonds at the interface of $\mathrm{ZnS}$ and $\mathrm{SiO}_{2} \cdot{ }^{35}$ The coating of these different inorganic passivation layers is evident in the TEM image of the photoanode (Fig. S6 $†$ ). However, the separate layers could not be distinguished in the $\sim 1.5 \mathrm{~nm}$ thick amorphous coating. The energy dispersive analysis of X-rays (EDAX) and elemental mapping in fact confirm the presence of $\mathrm{Zn}, \mathrm{S}, \mathrm{O}$ and $\mathrm{Si}$ elements.

To understand the role of passivation layers, QDs were deposited onto an insulating mesoporous $\mathrm{SiO}_{2}$ layer on FTO glass. Since there will be no charge injection from the QDs into the $\mathrm{SiO}_{2}$ layer, the changes in PL spectra (Fig. S7†) with different passivation layers can verify the significance of passivation. The PL intensity decreases by coating of an amorphous $\mathrm{TiO}_{2}$ layer onto the QDs due to injection of charge from QDs into $\mathrm{TiO}_{2}$. The PL intensity increases again by applying $\mathrm{ZnS}$ and $\mathrm{SiO}_{2}$ coatings over the film due to surface passivation of the QDs. $\mathrm{ZnS}$ and $\mathrm{TiO}_{2} / \mathrm{SiO}_{2}$ passivation however will be able to control neither the band edge recombination in QDs, nor the recombination pathways between QDs and the $\mathrm{TiO}_{2}$ photoanode which remain in contact without any interfacial layer. In fact these passivation layers at the interface of the photoanode and electrolyte potentially reduce or stop the back electron transfer from photoexcited electrons of QDs and from the conduction band of $\mathrm{TiO}_{2}$ to the electrolyte. A schematic is shown in Fig. 5 where the desired electron transfer pathways are shown by thicker curved arrows and the undesired recombination pathways are shown with dotted arrows. Overall, this strategic combination of alloying with $\mathrm{Zn}$ in AISE QDs, optimized ZnS layers and $\mathrm{TiO}_{2} / \mathrm{SiO}_{2}$ double passivation could significantly enhance the PCE of AISE based QDSSCs to $3.57 \%$, which is 23\% higher than the best of previous reports (Table 5). ${ }^{10,15-18,22,43-45}$

\section{Conclusions}

$\mathrm{Zn}^{2+}$-diffused AgInSe ${ }_{2}$ QDs with a Zn:(Ag + In) at\% of 36, 48 and 58 were synthesized by a hot-injection method and applied as light harvesters in QDSSCs. A majority of $\mathrm{Zn}^{2+}$ ions occupy the $\mathrm{In}^{3+}$ sites over $\mathrm{Ag}^{+}$sites. The QDs had a broad light harvesting range from the visible to the NIR region and the PL lifetime decreases with $\mathrm{Zn}^{2+}$-diffusion up to a $\mathrm{Zn}:(\mathrm{Ag}+\mathrm{In})$ at $\%$ of 48.2 (AZ5). The AISE and ZAISE QDs were ligand-exchanged with MPA to achieve a maximum loading of the QDs on the $\mathrm{TiO}_{2}$ photoanode. Apart from improving the crystallinity and carrier mobility of the QDs, diffusion of $\mathrm{Zn}^{2+}$ also tunes the intrinsic band gap. With 8 SILAR cycles of ZnS on top of the QD-deposited $\mathrm{TiO}_{2}$ photoanode the PCE was improved from $1.67 \%$ for AZ0 to $3.07 \%$ for AZ5. The passivation by ZnS reduces the surface trap state recombination whereas the nonradiative and donor-acceptor recombination processes likely remain unchanged. The PCE was further enhanced to $3.57 \%$ by dual inorganic passivation according to the $\mathrm{TiO}_{2} / \mathrm{QD} /$ amorphous $\mathrm{TiO}_{2} / \mathrm{ZnS} / \mathrm{SiO}_{2}$ configuration. In addition to the suppression of surface trap states, the surface passivation reduces the recombination pathways of back electron transfer from photoexcited electrons of QDs and also from the conduction band of $\mathrm{TiO}_{2}$ to the polysulfide redox electrolyte. The record PCE of $3.57 \%$ is so far the highest achieved for ternary $\operatorname{AgInX}_{2}(\mathrm{X}=\mathrm{S}, \mathrm{Se})$ based QDSSCs. A similar strategy coupled with a surface passivation approach is effective in enhancing the device efficiency of other low performing QD systems in photovoltaic applications. 


\section{Experimental section}

\subsection{Materials}

Silver nitrate $\left(\mathrm{AgNO}_{3}\right.$, Sigma Aldrich, 98\%), indium chloride tetrahydrate $\left(\mathrm{InCl}_{3} \cdot 4 \mathrm{H}_{2} \mathrm{O}\right.$, Sigma Aldrich, 99.999\%), oleylamine (Sigma Aldrich, $\geq 98 \%$ ), 1-octadecene (Sigma Aldrich, technical grade, 90\%), 1-dodecanethiol (Sigma Aldrich, $\geq 98 \%$ ), zinc acetate dihydrate $\mathrm{Zn}(\mathrm{OAc})_{2} \cdot 2 \mathrm{H}_{2} \mathrm{O}$ (Merck India, 98\%), zinc nitrate hexahydrate $\mathrm{Zn}\left(\mathrm{NO}_{3}\right)_{2} \cdot 6 \mathrm{H}_{2} \mathrm{O}$ (reagent grade, 98\%), sulfur powder (purified, Merck India), sodium sulfide flakes $\left(\mathrm{Na}_{2} \mathrm{~S} \cdot 9 \mathrm{H}_{2} \mathrm{O}\right.$, purified, Merck India), potassium chloride (purified, Merck India), chloroform (Emplura, Merck India), ethanol (Absolute, Changshu Yangyuan, China) and methanol (Sigma Aldrich, ACS spectrophotometric grade, 98\%) were used without further purification.

\subsection{Synthesis methodologies}

The synthesis of AISE QDs was performed by following a literature reported method with slight modifications. ${ }^{30}$

4.2.1 Preparation of selenium stock solution. $1 \mathrm{mmol}$ Se powder, $1 \mathrm{~mL}$ oleylamine and $1 \mathrm{~mL}$ dodecane thiol were taken in a round bottomed flask followed by evacuation and refilling with $\mathrm{N}_{2}$ three times at room temperature. Then the mixture was stirred under $\mathrm{N}_{2}$ to dissolve the Se powder.

4.2.2 Synthesis of AISE QDs. In a separate three neck round bottomed flask, $0.5 \mathrm{mmol} \mathrm{AgNO}_{3}, 0.5 \mathrm{mmol} \mathrm{InCl}_{3} \cdot 4 \mathrm{H}_{2} \mathrm{O}, 12 \mathrm{~mL}$ octadecene and $6 \mathrm{~mL}$ of oleylamine were loaded and cycled between vacuum and $\mathrm{N}_{2}$ three times at $60^{\circ} \mathrm{C}$. Then, the mixture was heated to $88^{\circ} \mathrm{C}$. When the target temperature was achieved, $2 \mathrm{~mL}$ of Se stock solution was rapidly injected into it. The solution immediately turned dark brown. The mixture was again heated to $180{ }^{\circ} \mathrm{C}$ for QD-growth and aged at this temperature for $5 \mathrm{~min}$. Finally, the reaction was quenched in a water bath and the product was isolated by precipitation with ethanol followed by centrifugation at $6500 \mathrm{rpm}$. The QDs were redispersed in chloroform for further use.

4.2.3 Synthesis of ZAISE QDs. $0.5 \mathrm{mmol} \mathrm{AgNO}_{3}, 0.5 \mathrm{mmol}$ $\mathrm{InCl}_{3} \cdot 4 \mathrm{H}_{2} \mathrm{O}$ and $\mathrm{Zn}(\mathrm{OAC})_{2} \cdot 2 \mathrm{H}_{2} \mathrm{O}$ (varied from 0.02 to 0.06 $\mathrm{mmol}$ ) were loaded into a three-neck round bottomed flask along with $6 \mathrm{~mL}$ of oleylamine and $12 \mathrm{~mL}$ of octadecene. The reaction mixture was cycled between vacuum and $\mathrm{N}_{2}$ three times at $60{ }^{\circ} \mathrm{C}$. Then, the mixture was heated to $88{ }^{\circ} \mathrm{C}$. When the temperature reached $85{ }^{\circ} \mathrm{C}$, the transparent colorless solution turned milky white. Then, $2 \mathrm{~mL}$ of Se-precursor solution was quickly injected into the above mentioned solution at $88^{\circ} \mathrm{C}$. The solution immediately turned dark brown and the mixture was further heated to $180{ }^{\circ} \mathrm{C}$ and kept at this temperature for $5 \mathrm{~min}$. Finally, the reaction mixture was quenched in a water bath and the mixture was precipitated with ethanol followed by centrifugation. Finally the ZAISE QDs were redispersed in $\mathrm{CHCl}_{3}$ and stored in the dark for further use.

4.2.4 Preparation of water soluble MPA-capped AISE and ZAISE QDs. The water soluble AISE and ZAISE QDs were prepared by replacing the initial hydrophobic oleylamine group with MPA. At first, $500 \mu \mathrm{L}$ MPA was taken into a vial along with 4 $\mathrm{mL} \mathrm{MeOH}$ and $1 \mathrm{~mL}$ distilled water. The $\mathrm{pH}$ of this solution was adjusted to 12 with $5 \mathrm{M} \mathrm{NaOH}$. $0.5 \mathrm{mmol}$ of AISE QDs dispersed into chloroform was taken into a separate vial and MPAmethanol solution was added to it followed by stirring for $4 \mathrm{~h}$. Post stirring, the mixture was allowed to stand for few minutes to separate the phases. The bottom organic layer was discarded. The upper aqueous layer containing the QDs was washed with acetone to remove free MPA molecules and QDs were redispersed in $6 \mathrm{~mL}$ water for further use.

4.2.5 Synthesis of $\mathrm{Cu}_{x} \mathrm{~S}$ nanostructures. $\mathrm{Cu}_{x} \mathrm{~S}$ nanostructures were synthesized by following our previously reported method. ${ }^{32} 5 \mathrm{mmol} \mathrm{Cu}\left(\mathrm{NO}_{3}\right)_{2} \cdot 6 \mathrm{H}_{2} \mathrm{O}$ and $5 \mathrm{mmol}$ sulfur powder in $100 \mathrm{~mL}$ ethylene glycol were taken in a round bottomed flask and irradiated in a microwave chamber at $125{ }^{\circ} \mathrm{C}$ for $12 \mathrm{~min}$ at $600 \mathrm{~W}$. The color of the solution changed from blue to deep green and a black colored product was precipitated. Finally, the product was washed with ethanol by centrifugation at $5000 \mathrm{rpm}$ for $5 \mathrm{~min}$ and dried at $80^{\circ} \mathrm{C}$ for $1 \mathrm{~h}$ to obtain the $\mathrm{Cu}_{x} \mathrm{~S}$ nanostructures.

\subsection{Fabrication of QDSSCs}

4.3.1 Preparation of the $\mathrm{TiO}_{2}$ photoanode. FTO coated glass (Solaronix, TCO 22-7, $2.2 \mathrm{~mm}$ thickness) pieces were cleaned ultrasonically with soap water followed by distilled water and ethanol. Three different layers of $\mathrm{TiO}_{2}$ were sequentially deposited onto the FTO glasses. At first, a compact layer was deposited by immersing the cleaned glasses into an aqueous solution of $40 \mathrm{mM} \mathrm{TiCl}_{4}$ at $80{ }^{\circ} \mathrm{C}$ for $45 \mathrm{~min}$ followed by washing with distilled water and ethanol. Active and scattering layers were deposited by the doctor blade technique. The active layer was prepared on top of the compact layer by using a $\mathrm{TiO}_{2}$ paste (Solaronix, Ti-Nanoxide T/SP, particle size $\sim 20 \mathrm{~nm}$ ) followed by annealing at $500{ }^{\circ} \mathrm{C}$ in air for $1 \mathrm{~h}$ in a furnace (film thickness $\sim 10 \mu \mathrm{m})$. A $\sim 4 \mu \mathrm{m}$ thick scattering layer of $\mathrm{TiO}_{2}$ (Solaronix, Ti-Nanoxide R/SP, particle size $\sim 100 \mathrm{~nm}$ ) was then coated on the active layer followed by annealing at $500{ }^{\circ} \mathrm{C}$ for another $1 \mathrm{~h}$.

4.3.2 Sensitization of the $\mathrm{TiO}_{2}$ photoanode. MPA-capped QDs were dispersed into $6 \mathrm{~mL}$ deionized water. $53 \mu \mathrm{L}$ of MPA was added to the dispersion and the $\mathrm{pH}$ was maintained at 12 with $5 \mathrm{M} \mathrm{NaOH}$. The $\mathrm{TiO}_{2}$ films were dipped into this solution for sensitization and kept for $24 \mathrm{~h}$. Finally, the QD sensitized $\mathrm{TiO}_{2}$ films were washed with distilled water and kept for further use.

4.3.3 Preparation of the $\mathrm{ZnS}$ passivation layer. To passivate the QD layer, a very thin layer of $\mathrm{ZnS}$ was employed onto the QD deposited $\mathrm{TiO}_{2}$ films by SILAR. At first, the QD-deposited $\mathrm{TiO}_{2}$ photoanode was dipped into an aqueous solution of $0.1 \mathrm{M}$ $\mathrm{Zn}\left(\mathrm{NO}_{3}\right)_{2} \cdot 6 \mathrm{H}_{2} \mathrm{O}$ solution for 1 min followed by rinsing with distilled water. The electrodes were further dipped into $0.1 \mathrm{M}$ $\mathrm{Na}_{2} \mathrm{~S} \cdot 9 \mathrm{H}_{2} \mathrm{O}$ solution for another $1 \mathrm{~min}$. The electrodes were further rinsed with distilled water to remove the unbound $\mathrm{S}^{2-}$ ions. The protocol was repeated to achieve the desired number of SILAR cycles.

4.3.4 Preparation of $\mathrm{TiO}_{2}$ and $\mathrm{SiO}_{2}$ double passivation layers. Amorphous $\mathrm{TiO}_{2}$ and $\mathrm{SiO}_{2}$ double passivation layers were prepared by following the literature reported method. ${ }^{34,35}$ At 
first, the QDSSCs before ZnS treatment were dipped into $10 \mathrm{mM}$ aqueous solution of $\mathrm{TiCl}_{4}$ and kept at $40^{\circ} \mathrm{C}$ for $30 \mathrm{~min}$ to create a very thin layer of amorphous $\mathrm{TiO}_{2}$ over the QD deposited $\mathrm{TiO}_{2}$ photoanode. Then the films were washed with distilled water followed by ethanol. Thereafter the ZnS passivation layer was applied as per the above protocol followed by rinsing with distilled water. These films were further immersed into an ethanolic solution of tetraethyl orthosilicate and kept for $2 \mathrm{~h}$. Finally the electrodes were washed with ethanol for further use.

4.3.5 Preparation of the $\mathrm{Cu}_{x} \mathrm{~S}$ counter electrode. A paste of $\mathrm{Cu}_{x} \mathrm{~S}$ was prepared by stirring overnight a mixture of $\mathrm{Cu}_{x} \mathrm{~S}$ nanostructures and polyvinyledene fluoride $(10: 1 \mathrm{w} / \mathrm{w})$ in $N$ methyl 2-pyrrolidone. The paste was doctor bladed on precleaned FTO, dried and annealed at $80{ }^{\circ} \mathrm{C}$ for $1.5 \mathrm{~h}$.

4.3.6 Electrolyte. A mixture of $2 \mathrm{M} \mathrm{Na}_{2} \mathrm{~S}, 2 \mathrm{M} \mathrm{S}$ and $0.2 \mathrm{M}$ $\mathrm{KCl}$ solutions in methanol/ $\mathrm{H}_{2} \mathrm{O}(3: 7 \mathrm{v} / \mathrm{v})$ was employed as the electrolyte.

4.3.7 Preparation of QDSSCs. The QDSSCs were prepared by assembling the counter electrode and the QD-sensitized photoanode using a $50 \mu \mathrm{m}$ thick parafilm spacer in a sandwich configuration. A $50 \mu \mathrm{L}$ droplet of the polysulfide electrolyte was employed between the two electrodes before assembling them. The active area was selected by employing a mask onto the working electrodes. The active area of the electrode was $0.23 \mathrm{~cm}^{2}$.

\subsection{Characterization}

The XRD measurements were carried out with a Rigaku powder $\mathrm{X}$-ray diffractometer having $\mathrm{Cu} \mathrm{K} \alpha=1.54059 \AA$ A radiation. The ICP-MS measurements were performed by using a Thermo Scientific X-series using Plasma lab software. TEM images were obtained with a UHR-FEG TEM system (JEOL, Model JEM 2100 F) using a $200 \mathrm{kV}$ electron source equipped with an energy dispersive X-ray spectroscope. To record the TEM images, EDAX and elemental mapping, the QD-sensitized photoanode with different inorganic coatings was crushed to powder and dispersed in isopropanol. UV-Vis absorbance spectra of the QD dispersion and the $\mathrm{TiO}_{2}$ photoanode were recorded using a Jasco V-670 spectrophotometer. To record the absorbance spectra of the $\mathrm{TiO}_{2}$ photoanode, the spectrophotometer was equipped with an integrating sphere. Room temperature PL spectra were measured with a Horiba Jobin Yvon Fluorolog using a Xe lamp as the excitation source with an excitation wavelength of $480 \mathrm{~nm}$. The fluorescence lifetimes were recorded by using a time correlated single-photon counting spectrofluorimeter from HORIBA Jobin Yvon IBH. The fluorescence life time was calculated by fitting the decay curves by using an iterative fitting program provided by IBH. Photovoltaic measurements were carried out by using a solar simulator provided by Newport using a $300 \mathrm{~W}$ xenon lamp as a light source. The intensity of the light was adjusted to $100 \mathrm{~mW} \mathrm{~cm} \mathrm{~cm}^{-2}$ by using a reference silicon solar cell in the presence of a $1.5 \mathrm{G}$ filter. The photovoltaic and the impedance measurements were carried out by using a CHI Electrochemical workstation. The plots were analyzed with inbuilt software in the electrochemical workstation.

\section{Acknowledgements}

GH thanks the University Grants Commission (UGC), New Delhi for her fellowship. GH also thanks Dr M. Venkataramanan for his help with the PL measurements and Mr Arjun Halder for the XRD measurements. The financial support from the Department of Science \& Technology - Science \& Engineering Research Board (DST-SERB) under Sanction No EMR/2016/001703 is duly acknowledged. SB thanks IISER Kolkata for the academic and research fund.

\section{Notes and references}

1 M. C. Beard, J. Phys. Chem. Lett., 2011, 2, 1282-1288.

2 A. Sahasrabudhe and S. Bhattacharyya, Chem. Mater., 2015, 27, 4848-4859.

3 O. E. Semonin, J. M. Luther, S. Choi, H.-Y. Chen, J. Gao, A. J. Nozik and M. C. Beard, Science, 2011, 334, 1530-1533.

4 A. J. Nozik, Chem. Phys. Lett., 2008, 457, 3-11.

5 P. V. Kamat, Acc. Chem. Res., 2012, 45, 1906-1915.

6 P. V. Kamat, J. Phys. Chem. C, 2007, 111, 2834-2860.

7 Z. Pan, K. Zhao, J. Wang, H. Zhang, Y. Feng and X. Zhong, ACS Nano, 2013, 7, 5215-5222.

8 Z. Pan, I. Mora-Seró, Q. Shen, H. Zhang, Y. Li, K. Zhao, J. Wang, X. Zhong and J. Bisquert, J. Am. Chem. Soc., 2014, 136, 9203-9210.

9 W. Li, Z. Pan and X. Zhong, J. Mater. Chem. A, 2015, 3, 16491655.

10 K. P. Kadlag, P. Patil, M. J. Rao, S. Datta and A. Nag, CrystEngComm, 2014, 16, 3605-3612.

11 M. G. Panthani, C. J. Stolle, D. K. Reid, D. J. Rhee, T. B. Harvey, V. A. Akhavan, Y. Yu and B. A. Korgel, J. Phys. Chem. Lett., 2013, 4, 2030-2034.

12 G. Halder and S. Bhattacharyya, J. Phys. Chem. C, 2015, 119, 13404-13412.

13 J. Krustok, J. Raudoja, M. Krunks, H. Mändar and H. Collan, J. Appl. Phys., 2000, 88, 205-209.

14 B. Mao, C.-H. Chuang, F. Lu, L. Sang, J. Zhu and C. Burda, J. Phys. Chem. C, 2013, 117, 648-656.

15 R. Bose, G. Manna, S. Jana and N. Pradhan, Chem. Commun., 2014, 50, 3074-3077.

16 M. Jagadeeswararao, A. Swarnkar, G. B. Markad and A. Nag, J. Phys. Chem. C, 2016, 120, 19461-19469.

17 Y. Wang, Q. Zhang, Y. Li and H. Wang, Nanoscale, 2015, 7, 6185-6192.

18 J. Han, Z. Liu, K. Guo, J. Ya, Y. Zhao, X. Zhang, T. Hong and J. Liu, ACS Appl. Mater. Interfaces, 2014, 6, 17119-17125.

19 D. Aldakov, A. Lefrançois and P. Reiss, J. Mater. Chem. C, 2013, 1, 3756-3776.

20 G. Hodes, J. Phys. Chem. C, 2008, 112, 17778-17787.

$21 \mathrm{H}$. McDaniel, N. Fuke, N. S. Makarov, J. M. Pietryga and V. I. Klimov, Nat. Commun., 2013, 4, 2887.

22 A. Guchhait and A. J. Pal, ACS Appl. Mater. Interfaces, 2013, 5, 4181-4189.

23 A. G. Pattantyus-Abraham, I. J. Kramer, A. R. Barkhouse, X. Wang, G. Konstantatos, R. Debnath, L. Levina, I. Raabe, 
M. K. Nazeeruddin, M. Grätzel and E. H. Sargent, ACS Nano, 2010, 4, 3374-3380.

24 J. Du, Z. Du, J.-S. Hu, Z. Pan, Q. Shen, J. Sun, D. Long, H. Dong, L. Sun, X. Zhong and L.-J. Wan, J. Am. Chem. Soc., 2016, 138, 4201-4209.

25 M. A. Ahmed, K. E.-S. Rady, K. M. El-Shokrofy, A. A. Arais and M. S. Shams, Mater. Sci. Appl., 2014, 5, 932-942.

26 J. E. Jaffe and A. Zunger, Phys. Rev. B: Condens. Matter, 1984, 29, 1882.

27 A. R. Kirmani, A. Kiani, M. M. Said, O. Voznyy, N. Wehbe, G. Walters, S. Barlow, E. H. Sargent, S. R. Marder and A. Amassian, ACS Energy Lett., 2016, 1, 922-930.

28 X. Tang, W. B. A. Ho and J. M. Xue, J. Phys. Chem. C, 2012, 116, 9769-9773.

29 B. Chen, H. Zhong, W. Zhang, Z. Tan, Y. Li, C. Yu, T. Zhai, Y. Bando, S. Yang and B. Zou, Adv. Funct. Mater., 2012, 22, 2081-2088.

30 D. Yao, H. Liu, Y. Liu, C. Dong, K. Zhang, Y. Sheng, J. Cui, H. Zhang and B. Yang, Nanoscale, 2015, 7, 18570-18578.

31 B. Mao, C.-H. Chuang, J. Wang and C. Burda, J. Phys. Chem. C, 2011, 115, 8945-8954.

32 D. Ghosh, G. Halder, A. Sahasrabudhe and S. Bhattacharyya, Nanoscale, 2016, 8, 10632-10641.

33 A. Sahasrabudhe, S. Kapri and S. Bhattacharyya, Carbon, 2016, 107, 395-404.
34 Z. Ren, J. Wang, Z. Pan, K. Zhao, H. Zhang, Y. Li, Y. Zhao, I. Mora-Sero, J. Bisquert and X. Zhong, Chem. Mater., 2015, 27, 8398-8405.

35 K. Zhao, Z. Pan, I. Mora-Seró, E. Cánovas, H. Wang, Y. Song, X. Gong, J. Wang, M. Bonn, J. Bisquert and X. Zhong, J. Am. Chem. Soc., 2015, 137, 5602-5609.

36 J.-Y. Kim, J. Yang, J. H. Yu, W. Baek, C.-H. Lee, H. J. Son, T. Hyeon and M. J. Ko, ACS Nano, 2015, 9, 11286-11295.

37 J. Tian and G. Cao, J. Phys. Chem. Lett., 2015, 6, 1859-1869.

38 K. Zhao, Z. Pan and X. Zhong, J. Phys. Chem. Lett., 2016, 7, 406-417.

39 N. Guijarro, J. M. Campiña, Q. Shen, T. Toyoda, T. LanaVillarreal and R. Gómez, Phys. Chem. Chem. Phys., 2011, 13, 12024-12032.

40 Z. Liu, M. Miyauchi, Y. Uemura, Y. Cui, K. Hara, Z. Zhao, K. Sunahara and A. Furube, Appl. Phys. Lett., 2010, 96, 233107.

41 Z. Ren, Z. Wang, R. Wang, Z. Pan, X. Gong and X. Zhong, Chem. Mater., 2016, 28, 2323-2330.

42 Z. Pan and X. Zhong, J. Mater. Chem. A, 2016, 4, 18976-18982.

43 T. Kameyama, Y. Douke, H. Shibakawa, M. Kawaraya, H. Segawa, S. Kuwabata and T. Torimoto, J. Phys. Chem. C, 2014, 118, 29517-29524.

44 S. M. Kobosko, D. H. Jara and P. V. Kamat, ACS Appl. Mater. Interfaces, DOI: 10.1021/acsami.6b14604.

45 C. Cai, L. Zhai, Y. Ma, C. Zou, L. Zhang, Y. Yang and S. Huang, J. Power Sources, 2017, 341, 11-18. 